\title{
Deep rectovaginal endometriotic nodules: perioperative complications from a series of 3,298 patients operated on by the shaving technique
}

\author{
Jacques Donnez • Pascale Jadoul • Sébastien Colette • \\ Mathieu Luyckx • Jean Squifflet • Olivier Donnez
}

Received: 27 April 2012 / Accepted: 14 June 2012 /Published online: 21 July 2012

(C) Springer-Verlag 2012

\begin{abstract}
The purpose of this study was to analyze complication and recurrence rates after deep endometriotic nodule surgery. A total of 3,298 cases of deep endometriotic nodules were analyzed. The shaving technique was used, avoiding bowel resection. Laparoscopic nodule resection was performed successfully in all cases. Major complications included: (1) rectal perforation in 42 cases $(1.3 \%)$, (2) ureteral retention ( $<5$ days) in 21 cases $(0.64 \%)$, (3) ureteral injury in 10 cases $(0.3 \%)$, and (4) fecal peritonitis in 1 case $(0.04 \%)$. This complication rate is much lower than that observed after bowel resection. In the same period, bowel resection was only required in $1.1 \%(n=37)$ of cases. Histology revealed circumscribed nodular aggregates of smooth muscle, endometrial glands, and scanty endometrial stroma. Lesions were found to be invaded by nerve fibers. Endometriosis is not cancer and does not require the same treatment approach. In young women, conservative surgery
\end{abstract}

J. Donnez $\cdot$ P. Jadoul $\cdot$ S. Colette $\cdot$ M. Luyckx $\cdot$ J. Squifflet Pôle de Recherche en Gynécologie, Institut de Recherche Expérimentale et Clinique (IREC),

Université Catholique de Louvain (UCL),

1200 Brussels, Belgium

J. Donnez $\cdot$ P. Jadoul $\cdot$ S. Colette $\cdot$ M. Luyckx $\cdot$ J. Squifflet Department of Gynecology, Cliniques Universitaires Saint-Luc, 1200 Brussels, Belgium

O. Donnez

Gynecology, CHU Mont-Godinne, Université Catholique de Louvain, 5530 Yvoir, Belgium

J. Donnez $(\bowtie)$

Department of Gynecology, Université Catholique de Louvain, Cliniques Universitaires St Luc,

Avenue Hippocrate 10,

1200 Brussels, Belgium

e-mail: jacques.donnez@uclouvain.be using the shaving technique means preservation of organs, nerves, and the vascular blood supply. The shaving technique yields low complication and recurrence rates and should be considered the first line in surgical approach in the case of deep endometriotic lesions.

Keywords Deep endometriosis $\cdot$ Nodules $\cdot$ Shaving technique $\cdot$ Bowel resection

\section{Introduction}

In 1996, we were the first to publish the concept of three different forms of endometriosis: (1) peritoneal endometriosis, (2) ovarian endometriosis, and (3) deep rectovaginal endometriosis $[1,2]$. The third form of the disease has been defined as deep endometriosis, rectovaginal endometriosis, or adenomyosis of the rectovaginal septum. In the literature, it is also called deep-infiltrating endometriosis or posterior deep-infiltrating endometriosis.

Many different surgical approaches have been proposed. The first study reporting the shaving technique and data from a series of 231 cases of laparoscopic management of deep endometriosis was published in Human Reproduction in 1995 [3], followed by a second study ( $n=$ 500 patients) published in BJOG in 1997 [4] and a third one ( $n=1,942$ patients) published in 2004 [5]. But surprisingly, the number of manuscripts advocating bowel resection has dramatically increased over recent years [6-15]. Koninckx et al. (see [16]) and Donnez et al. [17], firm advocates of the shaving technique, are increasingly confounded by this rapidly growing prevalence of bowel resection in the case of deep endometriosis with rectal muscularis involvement. During meetings on this topic, there is often heated debate between advocates of the two respective techniques. 
The goals of this manuscript are to present data from a consecutive series of 3,298 cases and discuss perioperative complications and recurrence rates by analyzing the existing literature and our own data.

\section{Patients and methods}

Three thousand, two hundred and ninety-eight patients operated on for deep endometriotic nodules were included in this study.

\section{Symptoms and diagnosis}

In this series of 3,298 patients, the main symptoms were pelvic pain and/or dysmenorrhea in $95 \%$ of cases, deep dyspareunia in $87 \%$ of cases, and rectal dyschezia in $44 \%$ of cases. About $45 \%$ of patients were suffering from pelvic pain associated with infertility. In all cases of infertility, evaluation of ovulation, cervical mucus-sperm interaction (postcoital test), and male factor (defined as $<15$ million sperm $/ \mathrm{ml}$ using a Makler counting chamber) were undertaken.

Careful clinical examination [18], transrectal ultrasonography (TRUS) [19], rectal endoscopic sonography [20], transvaginal sonography, barium enema, and magnetic resonance imaging (MRI) [21] have all been recommended to identify deep rectovaginal endometriotic lesions [22]. In our series, examination with a speculum revealed either a normal vaginal mucosa or a protruded bluish nodule in the posterior fornix. By palpation, the diameter of the lesion could be evaluated. Palpation is very often painful, and the presence of a nodule accounts for symptoms like deep dyspareunia and dysmenorrhea.

Preoperative radiography of the colon (barium enema) was systematically carried out in order to assess the involvement of the rectal surface. Profile radiography allows the best evaluation of infiltration of the anterior rectal wall. In our series, MRI and TRUS have also been systematically performed preoperatively since 1997, and Squifflet et al. [21] distinguished three types of deep lesions by analyzing their location, as precisely defined by the above procedures.

Surgery: the shaving technique

The shaving technique was already reported in a recent publication [17]. The principal steps involve (1) separation of the anterior rectum from the posterior vagina, (2) excision or ablation of deep endometriosis after complete dissection of the nodule from the posterior part of the cervix, and (3) resection of the posterior vaginal fornix and vaginal closure (Fig. 1).

Care must always be taken to preserve the pelvic autonomic nerves, as they are the pathway for the neurogenic

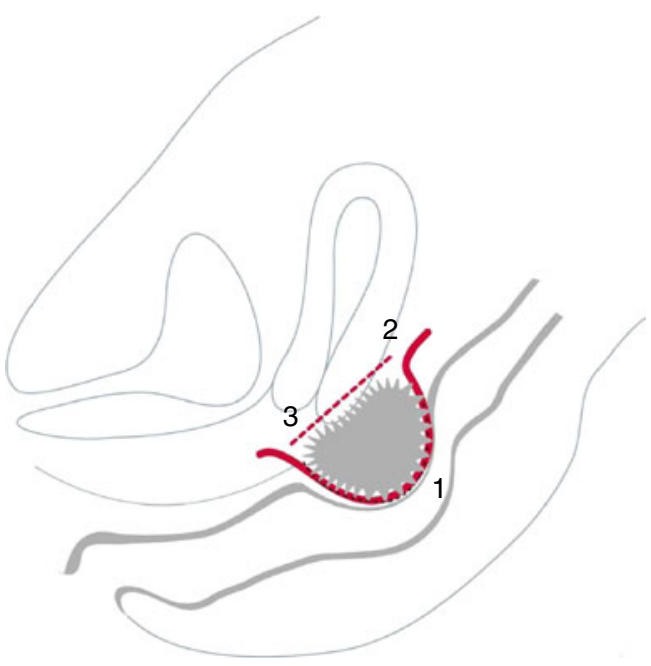

Fig. 11 Shaving to free the rectum, 2 resection of the nodule from the cervix, 3 resection of the posterior vaginal fornix

control of rectal, bladder, and sexual arousal function [23-27]. The shaving technique allows preservation of the nerves by avoiding deep lateral rectal dissection (necessary for rectosigmoid resection). Indeed, lateral dissection is mandatory only in the case of lateral extension of the disease with ureteral involvement $[17,28]$ and, even in this case, rarely involves dissection of the posterolateral compartment of the rectum.

\section{Histology}

All biopsies were dissected by an expert gynecologist, fixed in $4 \%$ formaldehyde, embedded in paraffin, and serially sectioned $(5 \mu \mathrm{m})$ for histological confirmation of endometriosis (presence of glands and stroma).

More recently, immunohistochemistry (IHC) was also performed using a standard immunoperoxidase method [29] to evaluate the expression of PGP9.5 (nerve marker). Briefly, endogenous peroxidase activity quenching, heat epitope retrieval, and blocking of nonspecific staining were carried out. The specimens were then incubated for $1 \mathrm{~h}$ at room temperature with rabbit polyclonal antihuman PGP9.5 (1/1,000, Dako, CA, USA), followed by incubation with secondary antibody conjugated to peroxidase (EnVision $+\mathrm{TM}$, Dako). The presence of peroxidase was revealed using 3,3'-diaminobenzidine (Dako), and specimens were counterstained with Mayer's hemalum solution (Merck, Darmstadt, Germany).

Human intestinal tissue was used as a positive control for PGP9.5 expression. Negative controls were processed using nonspecific $\mathrm{IgG}$ or omitting the specific primary antibodies.

Every fifth slide of each lesion was stained with hematoxylin-eosin to identify the section with the largest surface area of endometriotic glands and stroma, and the following 
serial section was immunostained with PGP9.5. Stromal surface area was delimited and measured using the MIRAX Viewer (MIRAX Viewer 1.12.22.0, Carl Zeiss MicroImaging $\mathrm{GmbH}$, Germany). Nerve fiber density was then determined in this stromal area, as well as in the area neighboring the lesion (up to $1.5 \mathrm{~mm}$ away).

\section{Results}

There is a big difference in symptoms and evolution between sigmoid and deep rectovaginal lesions. Symptoms of sigmoid endometriosis are mainly related to bowel stenosis and include cramps, constipation, and abdominal distension, while symptoms of deep rectovaginal lesions are dysmenorrhea, deep dyspareunia, and dyschezia.

Their pathogenesis is also different. Sigmoid lesions may be due to lymphatic or nervous system dissemination, while rectovaginal lesions are due either to metaplasia of Müllerian rests or to retrocervical extension of metaplastic nodules originating from either the cervix or the attachment area between the cervix and posterior vaginal fornix. Our manuscript focuses only on deep rectovaginal endometriosis and not sigmoid lesions.

Our series of 3,298 cases of deep rectovaginal endometriotic nodules treated by laparoscopy is presented in Table 1 . All patients were operated on between 1989 and 2010. Operating time ranged from 31 to 238 min (median, $78 \mathrm{~min}$ ), and median lesion size was $2.8 \mathrm{~cm}$ (range, 1$6 \mathrm{~cm})$. In the same period, 37 patients $(1.1 \%$, not included in the series of 3,298 ) underwent rectosigmoid bowel resection by laparotomy or laparoscopy-mini laparotomy,

Table 1 A series of 3,298 cases of deep endometriosis treated by the laparoscopic shaving technique without segmental resection

Laparoscopic shaving surgery $(n=3,298)$

\begin{tabular}{lc}
\hline Lesion size (cm) & $2.8(1-6)$ \\
Duration of surgery (min) & $70(31-238)$ \\
Hospitalization (days) & $2.7(2-7)$ \\
Complications & \\
•Rectal perforation during shaving & $42(1.3 \%)$ \\
• Fecal peritonitis requiring colostomy & $1(0.03 \%)$ \\
• Rectovaginal fistula & $2(0.06)$ \\
•Delayed hemorrhage (<24 h postoperatively) & $3(0.09 \%)$ \\
- Ureteral injury (transection) & $4(0.12 \%)$ \\
•Ureteral fistula (thermal damage) & $6(0.18 \%)$ \\
•Urinary retention (temporary, $<5$ days) & $21(0.64 \%)$
\end{tabular}

In 37 cases, bowel resection was carried out by laparotomy because of bowel stenosis with mucosal involvement (not included in the series of 3,298 patients). In this series of 37 cases, 27 were for recurrence of severe pain after shaving because of bowel lumen stenosis of more than $80 \%$ with circular stenosis (not only anterior involvement), as well as mucosal involvement visible on colonoscopy and confirmed by biopsy and histological evaluation. These three criteria (stenosis of the lumen $>80 \%$, circular stenosis, and mucosal involvement) are, in our view, indications for bowel resection, but they are infrequently encountered. Indeed, in our series, bowel resection was only required in $1.1 \%$ of cases.

In this series of 3,298 patients, laparoscopic dissection was performed successfully in all cases, even when radiography of the colon showed anterior bowel involvement of up to $5 \mathrm{~cm}$ or more.

\section{Lesion types according to MRI}

According to MRI, there are three types of lesions. These three types are: (a) type I, rectovaginal septum lesions; (b) type II, posterior vaginal fornix lesions; and (c) type III, hourglass-shaped lesions. Their prevalence is, respectively, 10,58 , and $32 \%$ of all deep nodular lesions [21].

The source of debate is the type III nodule. Indeed, these nodules occur when posterior fornix lesions extend cranially to the anterior rectal wall. As stated above, their prevalence is $32 \%$. Clinical evaluation usually reveals a larger lesion (more than $3 \mathrm{~cm}$ ) (mean, $4.2 \mathrm{~cm}$; range, $3-6 \mathrm{~cm}$ ), and barium enema always shows infiltration and retraction of the rectal muscularis, known as perivisceritis. This continuum between the rectal muscularis and the cervix is found to obliterate the rectovaginal septum cranially. A clearly defined continuum exists between these two parts of the lesion. This is why we termed these lesions diabolo-like or hourglass-shaped (Fig. 2).

These lesions always occur under the peritoneal fold of the recto-uterine pouch of Douglas. Infiltration of the rectal muscularis is systematically observed in this subtype, as demonstrated by barium enema (profile image) and TRUS, but infiltration is generally limited to the muscularis without mucosal involvement (Fig. 3). They may also extend laterally and involve the ureter $[17,28$, $30,31]$.

It is essentially the treatment of these type III nodules that causes such contention and debate among surgeons.

2. Peri- and postoperative complications (Table 1)

In our series of 3,298 cases, laparoscopic rectal perforation occurred in 42 cases $(1.3 \%)$. All perforations were diagnosed at the time of laparoscopy. In the first three cases (in the early 1990s), the rectum was repaired by laparotomy and, in all others, by laparoscopy. Laparoscopic suture was carried out through a full-thickness layer using Vicryl 2.0 (Ethicon, Johnson and Johnson, USA) with separate stitches. The area was finally covered with fibrin glue (Tissucol, Johnson and Johnson, 

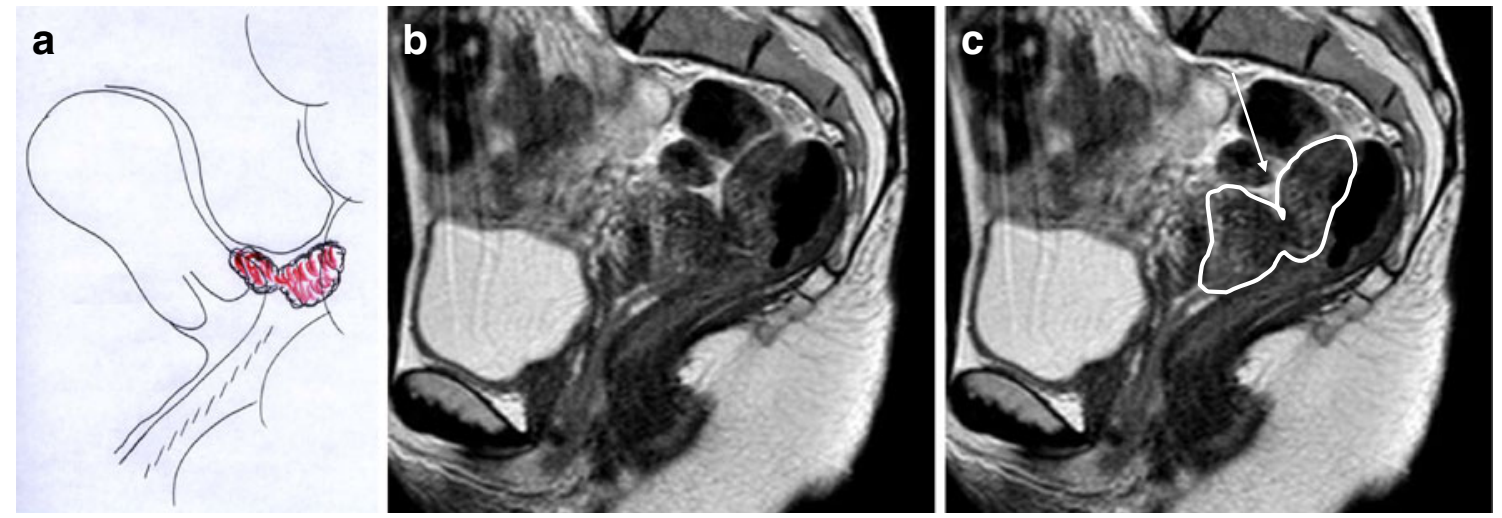

Fig. 2 a Type III nodule; $\mathbf{b}$ and $\mathbf{c}$ MRI: type III nodule; the nodule extends from the posterior part of the cervix to the anterior rectal wall and an "hourglass" shape can be seen

USA). Among the 42 cases, neither fistula nor any other complications were observed.

Rectal muscle defects frequently arise during the shaving procedure and are repaired by suturing. If the rectal lumen is not entered, it is not considered a complication, just part of the procedure. It should be noted, however, that in the early years of shaving practice, rectal muscularis defects were not closed, and that two cases $(0.06 \%)$ of rectovaginal fistula occurred 6 to 8 days after surgery. Both cases were treated conservatively by antibiotics and diet for 10 days.

One case of fecal peritonitis occurred 7 days after surgery. During surgery, bleeding at the site of lateral dissection of the rectum required extensive bipolar coagulation. At the end of surgery, bowel integrity was checked by $\mathrm{CO}_{2}$ intrarectal insufflation and the blue test. No rectal defect was diagnosed. Seven days later, a hole of $2.5 \mathrm{~cm}$ in size was detected. Extensive coagulation probably provoked thermal rectal injury, with subsequent necrosis and a fistula. A colostomy was

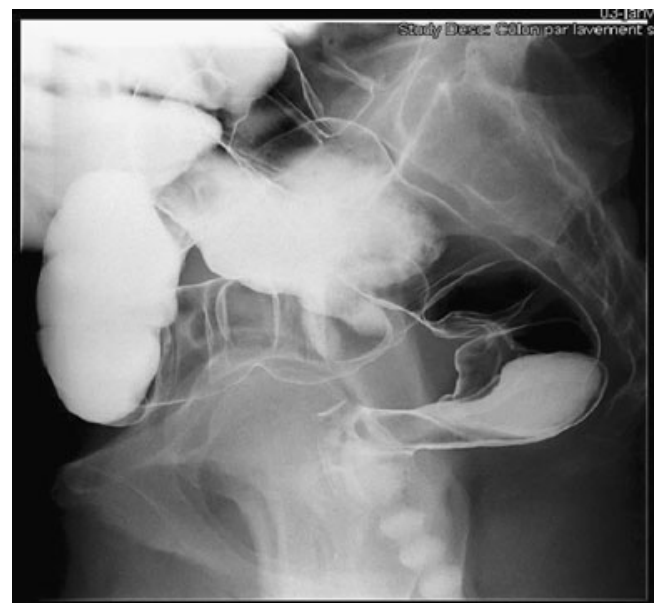

Fig. 3 Barium enema: infiltration of the muscularis of the anterior rectal wall therefore carried out. Three months later, the colostomy was closed.

Ten cases $(0.3 \%)$ of ureteral injury were noted in our patients. Four cases $(0.1 \%)$ of ureteral transection were diagnosed on the first postoperative day by the presence of abundant fluid in the peritoneal cavity. High levels of urea and creatinine in the "peritoneal" fluid and intravenous pyelography (IVP) confirmed the diagnosis. Nephrostomy was carried out. One case resolved spontaneously with complete healing of the ureter 2 months later. The other three cases required vesico-ureteral reimplantation.

The remaining six cases $(0.2 \%)$ of ureteral injury were due to thermal damage (bipolar coagulation) and were treated by insertion of a JJ stent, which was removed 3 months later. Among these six patients, four recovered completely. Two women needed vesicoureteral reimplantation for hydronephrosis due to stenosis of the lower ureteral segment (fibrosis). In these cases, hydronephrosis was detected approximately 1 month after removal of the JJ stent. This is why, in the case of large nodules with possible ureteral involvement (suspected by MRI or IVP), a JJ stent is inserted before starting the laparoscopic procedure, and ureterolysis is then performed $[17,28]$. The usefulness of JJ stents in preventing subsequent complications was recently confirmed by Weingertner et al. [32]. The group of Koninckx also published a large series of ureteral injuries [16]. They demonstrated that ureteral repair was often possible by laparoscopy with excellent outcomes.

Urinary retention occurred in 21 cases $(0.64 \%)$. All were patients with large nodules $(>4 \mathrm{~cm})$ and bilateral extension, requiring extensive lateral dissection. A Foley catheter was inserted for 2 days, and all but two cases resolved spontaneously. These last two cases required bladder catheterization for 5 days, then resolved. 
3. Recurrence and pregnancy rates

Recurrence and pregnancy rates could only be analyzed in a prospective study. This was done in a prospective series of 500 patients operated on by the shaving technique for deep rectovaginal endometriotic nodules (types II and III). This series was recently published [17].

In case of type I nodules, recurrence was shown to be well under $5 \%$ [5]. In types II and III, recurrence of severe pelvic pain was $7 \%$ (36 of 500) [17] and was found to be significantly lower $(p<0.05)$ in women who became pregnant after surgery $(3.6 \%)$ than those who did not $(14 \%)$.

4. Histology

Deep endometriosis associated or not with pelvic endometriosis can take the form of nodular masses involving the posterior vaginal fornix. They have been called "adenomyotic nodules of the rectovaginal septum" [5]. An adenomyoma is a circumscribed nodular aggregate of smooth muscle, endometrial glands and, usually, endometrial stroma (Fig. 4). This type of lesion is a specific form called adenomyosis, characterized by the presence of abundant muscular tissue invaded by glandular epithelium, covered with scanty stroma [4]. Nodular lesions exhibit a varied functional response to ovarian hormones. They may not respond to physiologic levels of progesterone, and secretory changes are frequently absent or incomplete during the second half of the cycle $[1,2]$. In our study, endometriotic glands and stroma were often found by serial section up to the vaginal mucosa (Fig. 4), which was sometimes replaced by endometrial epithelium, confirming the need to remove the posterior vaginal fornix, as already suggested in our first series of publications.

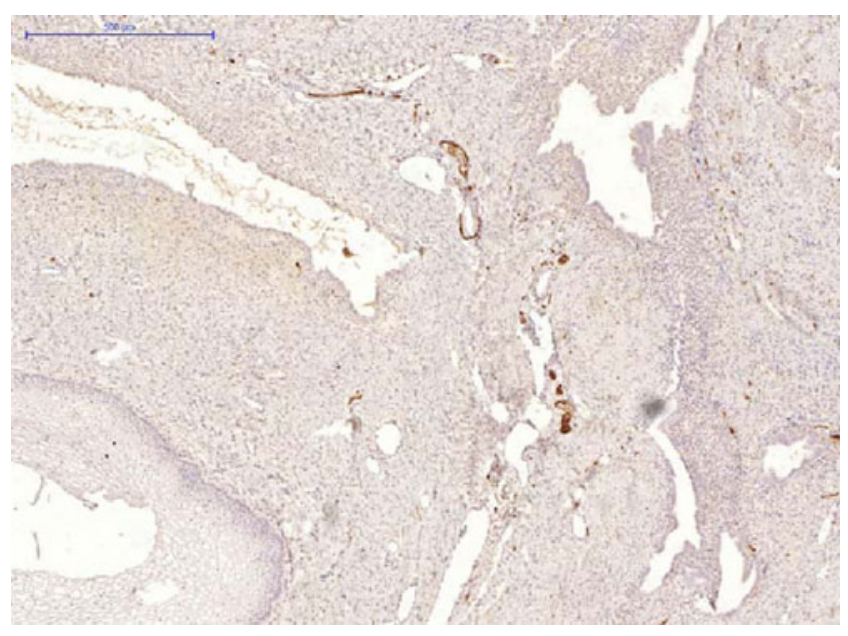

Fig. 4 Type III nodule (histology): aggregate of smooth muscle, endometrial glands, and scanty stroma. The vaginal mucosa is clearly visible (on the left side)
In a preliminary study, mentioned in the methods, we were able to demonstrate the presence of nerve fibers (PGP9.5-positive) in deep endometriotic lesions. All deep-infiltrating endometriosis (affecting the rectovaginal septum or rectal muscularis) was found to be invaded by nerve fibers, especially around intestinal tissue. The closer the lesion was to the digestive tract, the higher the nerve fiber density (data not shown) (Fig. 5).

\section{Discussion}

The first two large series including 231 and 500 women undergoing surgery for deep rectovaginal endometriosis were published in 1995 and 1997, respectively [3, 4]. The conclusion, already back in 1997, was that it is prudent to curtail rather than encourage the widespread use of an aggressive and potentially morbid procedure. Nevertheless, increasingly aggressive surgery, including bowel resection, is still systematically proposed in the case of deep endometriosis with muscularis involvement, even in the absence of mucosal involvement [6-11, 14, 15, 20, 33, 34].

The debate is not new. In a paper by Hudelist et al. [35], different past series and theories on the etiology of adenomyosis and endometriosis are described, and we are shown a specimen of deep endometriosis involving the rectum (a typical hourglass-shaped nodule). Back in 1903, Füth reported a case of rectal shaving for a hard mass between the uterus and the rectum [36] (Fig. 6a). In 1912, Renish performed resection of the anterior rectal wall (the first "disk resection") (Fig. 6b) together with hysterectomy [37], while Lockyer performed hysterectomy and bowel resection over a length of $20 \mathrm{~cm}$ for the same type of lesion (drawing by Lockyer from 1918) [38].

Almost 100 years later, the debate still rages on, not only rearing its head during the World Congress on Endometriosis in Melbourne [39], but also in the literature, with two

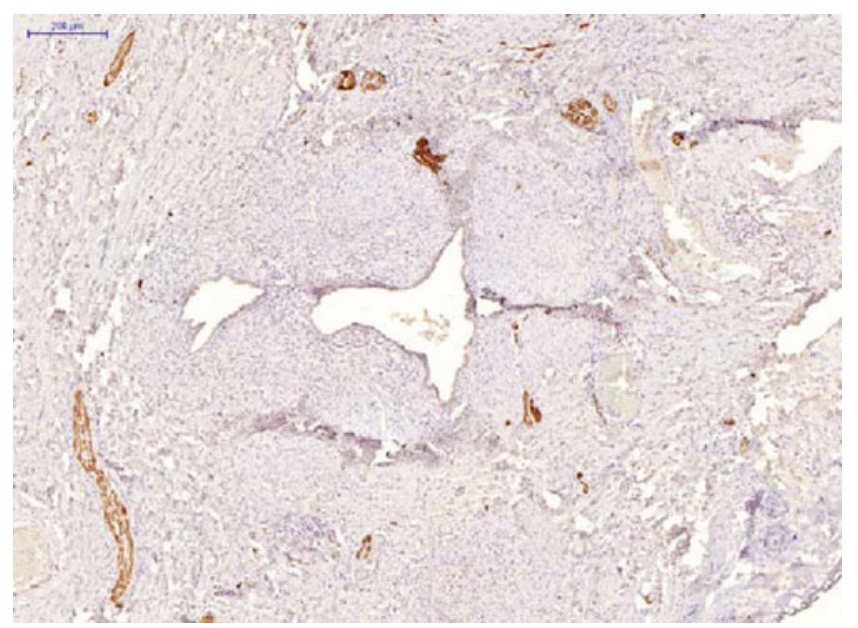

Fig. 5 Deep rectovaginal nodule. IHC: sections were immunostained with PGP9.5; abundant nerve fibers are visible 
Fig. 6 a First case of rectal shaving published by Füth, who performed total hysterectomy revealing a hard thick mass fixed to the rectum, which was removed "to a major extent leaving the rectum behind". b First case of disk resection by Renish [37], showing deep endometriotic nodule (hourglass-shaped) with rectal mucosal involvement

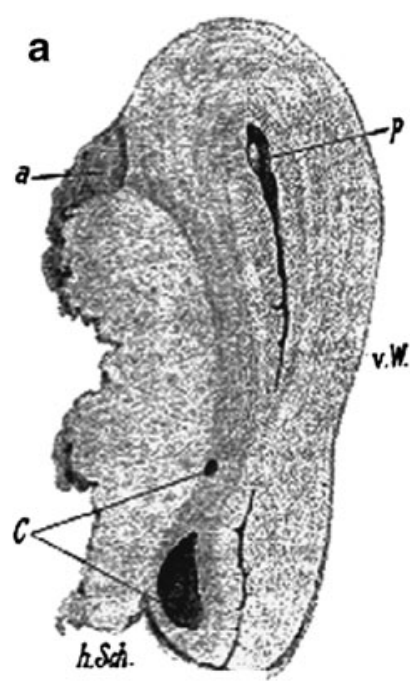

b

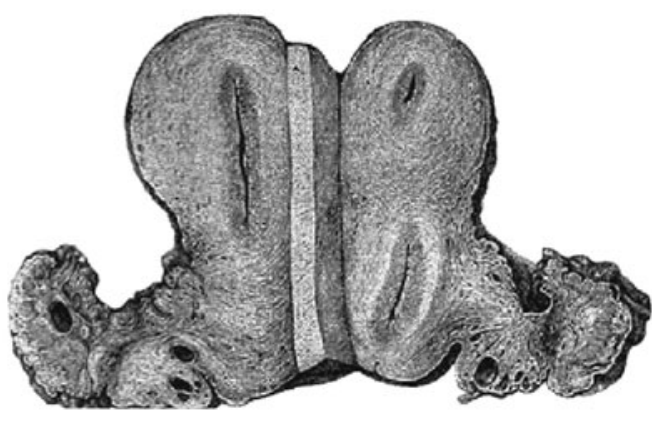

Hudelist. The migruting adenowyoma. Fentil Steril 2009 conflicting articles recently appearing in the same journal: "Should we operate for deep-infiltrating endometriosis? No. Choose realism instead of idealism!" by Fernandez et al. [40] and: "Yes, patients with deep-infiltrating endometriosis should be operated! Prefer optimistic will to pessimistic intelligence!" by Canis et al. [41].

\section{Complications}

We conducted a review of complication rates encountered after bowel resection for deep nodular endometriosis [6-15, 42] (Table 2.). Unfortunately, much of the recent literature appears to encourage very invasive techniques, including bowel resection in case of rectal muscularis involvement. Our review of recent publications reporting the results and complications of laparoscopy-assisted bowel resection for deep endometriotic nodules reveals a relatively high complication rate compared to the shaving technique ([17 and present data). Indeed, rates of urinary retention (3-10\%), ureteral lesions (2-4\%), fecal peritonitis (3-5\%), severe anastomotic stenosis (3\%), rectovaginal fistulas (6-9\%), and pelvic abscesses (2-4\%) were found to be significantly higher than with the shaving technique. A possible bias could have been the relatively small number of patients involved in some series, but it should be pointed out that, even in very experienced hands [12, 42], the rate of severe complications (rectovaginal fistulas, abscesses, stenosis, fecal peritonitis) can be more than $10 \%$.

In 2009, Meuleman et al. reported an $11 \%$ rate of severe complications, some of which were due to the duration of surgery (mean over $7 \mathrm{~h}$ ) [14]. Indeed, lower leg compartment syndrome was observed in three cases (3 of 56),
Table 2 Complication rate after the shaving technique compared to bowel resection (metaanalysis)

\begin{tabular}{|c|c|c|}
\hline & $\begin{array}{l}\text { Shaving technique } \\
\text { (personal data), } n=3,298\end{array}$ & $\begin{array}{l}\text { Rectal resection (meta-analysis) } \\
\text { (Redwine and Wright [6], Chapron } \\
\text { et al. [7], Daraï et al. [8, 42], Emmanuel } \\
\text { and Davis [9], Fleisch et al. [10], Ford } \\
\text { et al. [11]; Keckstein and Wiesinger } \\
\text { [12]; Mereu et al. [13], Meuleman } \\
\text { et al. [14, 15]) }\end{array}$ \\
\hline Repeat surgery & $<0.1 \%$ & $10 \%$ \\
\hline Urinary retention & $0.64 \%$ & $3-10 \%$ \\
\hline Ureteral lesions (uroperitoneum) & $0.3 \%$ & $2-4 \%$ \\
\hline Severe anastomotic stenosis & - & $3 \%$ \\
\hline Sepsis (pelvic abscess) & $0.03 \%$ & $2-4 \%$ \\
\hline $\begin{array}{l}\text { Rectal perforation upon shaving } \\
\text { (diagnosed and repaired during } \\
\text { surgery, no further complications) }\end{array}$ & $1.3 \%$ & - \\
\hline Rectovaginal fistula & $0.06 \%$ & $6-9 \%$ \\
\hline Fecal peritonitis, anastomotic leakage & $0.06 \%$ & $3-5 \%$ \\
\hline
\end{tabular}


requiring a fasciotomy. It is important to note that there was no mucosal infiltration of the rectum in this series. This relatively high rate of severe complications was encountered despite a multidisciplinary approach including a urologist and digestive surgeon. In this series, the median operating time was $7 \mathrm{~h}$ and $56 \mathrm{~min}$ (range, 180-780 $\mathrm{min}$ ). The duration is also related to costs for the hospital (operating room, nurses, anesthesist...).

In our series, the median operating time (including laparoscopy) was just $78 \mathrm{~min}$ (range, 31-248 $\mathrm{min}$ ). Surgery only exceeds $3 \mathrm{~h}$ when nodules are removed from the bladder, ureter, and bowel, sometimes including laparoscopic nephrectomy during the same procedure, as described by Jadoul et al. [30].

It should also be pointed out that colorectal segmental resection is a complex procedure, sometimes resulting in pelvic nerve damage and unpleasant urinary and digestive symptoms [26, 27, 43-46]. Indeed, urinary retention is quite frequent (3-10\%) after bowel resection, as often this type of surgery cannot preserve the pelvic autonomic nerves, which are the pathway for the neurogenic control of bladder function. Interestingly, the shaving technique provokes a very low rate of urinary retention because the dissection usually respects, at least on one side, the sympathetic nerves passing laterally to the rectum, which are frequently cut during extensive rectal or rectosigmoidal resection.

In our view, removing part of the rectum is simply not justified, since we know that this technique increases the risk of complications. Furthermore, no randomized studies performed to date have been able to prove that it is any more effective than the shaving technique. The recent review by Meuleman et al. [15] fails to give arguments in favor of bowel resection because of the absence of any real classification of the lesions (e.g., level of lesion, type of infiltration...) or surgery (e.g., rectal, sigmoid, rectosigmoid resection, length...). Landi et al. [25] reported that fullthickness disk excision using a circular stapler could prevent potential morbidity associated with low anastomosis. As only a few months earlier the same group [13] reported a major complication rate that required repeat operations in 20 out of 192 cases $(10.4 \%)$, they are now probably evaluating a less aggressive surgical technique than bowel resection [25]. The same trend away from bowel resection toward a less aggressive approach has recently been described by Slack et al. and Roman et al. [43, 47].

The shaving approach is often more than adequate. For type I and II lesions, there is a general consensus that in the absence (or virtual absence) of muscularis infiltration, there is no need for bowel resection. But the controversy arises when muscularis infiltration is present. This infiltration, observed in all cases of type III lesions, may usually be left in place, at least partially, since the shaving technique already removes what is necessary. Residual lesions in the muscularis of the rectum do not evolve and remain constant for a long time [5]. The argument used by some gynecologists and surgeons to defend bowel resection is that this procedure is more "radical." This is simply not true. Indeed, even with bowel resection, the margins are not free of disease in more than $10 \%$ of cases [47, 48], so their argument is not borne out. Moreover, we should bear in mind that radical bowel surgery is associated with long-term morbidity, and as previously reported in a Cochrane Review [49], quality of life is significantly impaired following anterior resection.

\section{Recurrence}

The recurrence rate of symptoms (severe dysmenorrhea, severe dyspareunia, and severe pelvic pain) evaluated prospectively was $7 \%$ after shaving surgery in a recent study of 500 cases of type II and III nodules [17]. The rate of recurrent pain observed in this large series was therefore no higher than that encountered after more aggressive surgery, including bowel resection. In the majority of series reporting data on bowel resection, the recurrence rate of severe pelvic pain is evaluated to be $6-20 \%[6-14,42]$. However, in these studies, it is difficult to gauge the proportion of women suffering from pelvic pain due to a genuine recurrence of endometriosis and those with postoperative adhesions related to severe complications, such as pelvic abscesses or peritonitis.

The favorable results observed in our study [17] in terms of pelvic pain recurrence may be explained by the almost complete resection of deep nodular endometriosis, which is innervated abundantly by sensory $\mathrm{C}$ chlorogenic and adrenergic nerve fibers, as recently demonstrated by Wang [50].

Nerve fibers were identified not only in the eutopic endometrium of endometriosis patients [51, 52], but also in endometriotic lesions themselves. This was especially true of deep-infiltrating endometriosis $[50,53]$ and, to a lesser extent, peritoneal lesions [54], while it was more controversial in the case of ovarian endometriomas [53-56].

Our preliminary investigations confirm high nerve fiber density in deep-infiltrating lesions. Moreover, it was shown that this high density was mainly observed in deep lesions located near the intestinal lining. Some studies have suggested a correlation between nerve fiber density and pain in endometriosis patients $[53,54]$. However, since pain is a suggestive feeling, larger patient populations suffering from different forms of endometriosis should be examined and compared with a disease-free population to conclusively establish a correlation between nerve fiber presence and pain felt by patients. Nevertheless, the present results, associated with previous findings, could explain the painful symptoms encountered by patients suffering from deepinfiltrating endometriosis and the good results in terms of 
improvement in symptoms after almost complete resection of deep nodules by the shaving technique.

On the other hand, as previously stated, even when bowel resection is carried out, the margins are not free of disease in around $10 \%$ of cases $[48,57]$. During the study period, 37 patients underwent bowel resection because of bowel stenosis $(>80 \%)$ with mucosal involvement. Among these 37 women, 27 were operated on for recurrence of severe pain with bowel stenosis after shaving (among the 3,298 cases). The fact that only 27 women underwent surgery (bowel resection) for recurrence is an important argument to consider, indicating that bowel resection should not be undertaken as first-line therapy but as a second-line approach in the case of recurrence with stenosis $>80 \%$.

As we have stressed since 1997 and as vigorously discussed at the WES Congress in Melbourne [39], it is time to discourage very aggressive surgery under the false pretenses that a more radical approach is more effective. It is certainly not true of endometriosis, which is a benign disease. Women want to be free of symptoms, have normal bladder and digestive function, and enjoy a normal sex life. They do not necessarily want to be completely free of endometriosis. Indeed, as stated by Vercellini et al. [58, 59], the overall extent of disease correlates neither with the frequency or severity of symptoms, nor with the long-term prognosis in terms of conception or pain recurrence. The question raised by Koninckx and Ussia [60] "Do we need centers of excellence in endometriosis surgery or centers of excellence in endometriosis?" is still pertinent.

\section{Conclusion}

Endometriosis is not cancer and does not require the same treatment approach. Conservative surgery for deep endometriosis in young women means preservation of organs, nerves, and the vascular blood supply. There is therefore a need for further strong and energetic debate to weigh up the benefits of shaving (debulking surgery) versus rectal resection (radical surgery). Feasibility is not always synonymous with efficacy. As already pointed out, in the early twentieth century, Füth [36] carried out the first rectal shaving procedure and Renish [37] the first disk resection, while Lockyer [38] performed bowel resection for deep endometriosis involving the anterior rectal wall. One century later, the debate still rages on....

Conflict of interest This study was supported by grants to the institution from the Fonds de la Recherche Scientifique-FNRS, Belgium (no. 1.5015.11), la Région Wallonne, Vicomte Philippe de Spoelberch, Baron Frère and Mr. Pietro Ferrero.

\section{References}

1. Donnez J, Nisolle M, Smoes P, Gillet N, Beguin S, Casanas-Roux F (1996) Peritoneal endometriosis and "endometriotic" nodules of the rectovaginal septum are two different entities. Fertil Steril 66:362-368

2. Nisolle M, Donnez J (1997) Peritoneal endometriosis, ovarian endometriosis, and adenomyotic nodules of the rectovaginal septum are three different entities. Fertil Steril 68:585-596

3. Donnez J, Nisolle M, Casanas-Roux F, Bassil S, Anaf V (1995) Rectovaginal septum endometriosis or adenomyosis: laparoscopic management in a series of 231 patients. Hum Reprod 10:630-635

4. Donnez J, Nisolle M, Gillerot S, Smets M, Bassil S, Casanas-Roux F (1997) Rectovaginal septum adenomyotic nodules: a series of 500 cases. Br J Obstet Gynaecol 104:1014-1018

5. Donnez J, Squifflet J (2004) Laparoscopic excision of deep endometriosis. Obst Gynecol Clinics N Am 31:567-580

6. Redwine DB, Wright JT (2001) Laparoscopic treatment of complete obliteration of the cul-de-sac associated with endometriosis: long-term follow-up of en bloc resection. Feril Steril 76:358-365

7. Chapron C, Chopin N, Borghese B, Malartic C, Decuypere F, Foulot H (2004) Surgical management of deeply infiltrating endometriosis: an update. Ann NY Acad Sci 1034:326-337

8. Daraï E, Marpeau O, Thomassin I, Dubernard G, Barranger E, Bazot M (2005) Fertility after laparoscopic colorectal resection for endometriosis: preliminary results. Fertil Steril 84:945-950

9. Emmanuel KR, Davis C (2005) Outcomes and treatment options in rectovaginal endometriosis. Curr Opin Obstet Gynecol 17:399 402

10. Fleisch MC, Xafis D, Bruyne FD, Hucke J, Bender HG, Dall P (2005) Radical resection of invasive endometriosis with bowel or bladder involvement-long-term results. Eur J Obstet Gynecol Reprod Biol 123:224-229

11. Ford J, English J, Miles WF, Giannopoulos T (2005) A new technique for laparoscopic anterior resection for rectal endometriosis. JSLS 9:73-77

12. Keckstein J, Wiesinger H (2006) The laparoscopic treatment of intestinal endometriosis. In: Sutton C, Jones K, David Adamson G (eds) Endometriosis. Taylor \& Francis, U.K., pp 177-187

13. Mereu L, Gagliardi ML, Clarizia R, Mainardi P, Landi S, Minelli L (2010) Laparoscopic management of ureteral endometriosis in case of moderate-severe hydroureteronephrosis. Fertil Steril 93:46-51

14. Meuleman C, D'Hoore A, Van Cleynenbreugel B, Beks N, D'Hooghe T (2009) Outcome after multidisciplinary $\mathrm{CO}_{2}$ laser laparoscopic excision of deep infiltrating colorectal endometriosis. Reprod BioMed Online 18:282-289

15. Meuleman C, Tomasseti C, D'Hoore A, Buyens A, Van Cleynenbreugel B, Fieuws S, Penninckx F, Vergote I, D’Hooghe $\mathrm{T}$ (2011) Clinical outcome after $\mathrm{CO}_{2}$ laser laparoscopic radical excision of endometriosis with colorectal wall invasion combined with laparoscopic segmental bowel resection and reanastomosis. Hum Reprod 26:2336-2343

16. De Cicco C, Schonman R, Craessaerts M, Van Cleynenbreugel B, Ussia A, Koninckx PR (2009) Laparoscopic management of ureteral lesions in gynecology. Fertil Steril 92:1424-1427

17. Donnez J, Squifflet J (2010) Complications, pregnancy and recurrence in a prospective series of 500 patients operated on by the shaving technique for deep rectovaginal endometriotic nodules. Hum Reprod 25:1949-1958

18. Koninckx PR, Meuleman C, Oosterlynck D, Cornillie FJ (1996) Diagnosis of deep endometriosis by clinical examination during menstruation and plasma CA-125 concentration. Fertil Steril 65:280-287

19. Ohba T, Mizutani H, Matsuura K, Ito M, Okamura H (1992) Transrectal ultrasonographic detection of uterosacral ligaments- 
preliminary study for ultrasonographic evaluation of endometriosis. Nippon Sanka Fujinka Gakkai Zasshi 44:1187-1188

20. Abrao MS, Gonçalves MO, Dias JA Jr, Podgaec S, Chamie LP, Blasbalg R (2007) Comparison between clinical examination, transvaginal sonography and magnetic resonance imaging for the diagnosis of deep endometriosis. Hum Reprod 22:3092-3097

21. Squifflet J, Feger C, Donnez J (2002) Diagnosis and imaging of adenomyotic disease of the retroperitoneal space. Gynecol Obstet Invest 54:43-51

22. Nightingale AL, Ballard KD, Wright JT (2010) Evidence-based gynaecological practice: clinical review 3 . The use of imaging for pre-operative planning in deep infiltrating endometriosis involving the rectum. Gynecol Surg 7:407-415

23. Maas K, Moriya Y, Kenter G, Trimbos B, van de Velde C (1999) A plea for preservation of the pelvic automatic nerves. Lancet 354:772-773

24. Possover M, Diebolder H, Plaut K, Schneider A (2000) Laparoscopically assisted vaginal resection of rectovaginal endometriosis. Obstet Gynecol 96:304-307

25. Landi S, Ceccaroni M, Perutelli A, Allodi C, Barbieri F, Fiaccavento A et al (2006) Laparoscopic nerve-sparing complete excision of deep endometriosis: is it feasible? Hum Reprod 21:774-781

26. Roman H, Vassilieff M, Gourcerol G, Savoye G, Leroi AM, Marpeau L et al (2011) Surgical management of deep infiltrating endometriosis of the rectum: pleading for a symptom-guided approach. Hum Reprod 26:274-281

27. Vassilieff M, Suaud O, Collet-Savoye C, Da Costa C, MarouteauPasquier N, Belhiba H, Tuech JJ, Marpeau L, Roman H (2011) Computed tomography-based virtual colonoscopy: an examination useful for the choice of the surgical management of colorectal endometriosis. Gynecol Obstet Fertil 39:339-345

28. Donnez J, Nisolle M, Squifflet J (2002) Ureteral endometriosis: a complication of rectovaginal endometriotic (adenomyotic) nodules. Fertil Steril 77:32-37

29. Colette S, Defrère S, Lousse JC, Van Langendonckt A, Gotteland JP, Loumaye E, Donnez J (2011) Inhibition of steroid sulfatase decreases endometriosis in an in vivo murine model. Hum Reprod 26(6):1362-1370

30. Jadoul P, Feyaerts A, Squifflet J, Donnez J (2007) Combined laparoscopic and vaginal approach for nephrectomy, ureterectomy, and removal of a large rectovaginal endometriotic nodule causing loss of renal function. J Minim Invasive Gynecol 14:256-259

31. Koninckx P, Ussia A, Adamyan L, Wattiez A (2011) An endometriosis classification, designed to be validated. Gynecol Surg 8:1-6

32. Weingertner AS, Rodriguez B, Ziane A, Gibon E, Thoma V, Osario F et al (2008) The use of JJ stent in the management of deep endometriosis lesion, affecting or potentially affecting the ureter: a review of our practice. BJOG 115:11591164

33. Chapron C, Liaras E, Fayet P, Hoeffel C, Fauconnier A, Vieira M et al (2002) Magnetic resonance imaging and endometriosis: deeply infiltrating endometriosis does not originate from the rectovaginal septum. Gynecol Obstet Invest 53:204-208

34. Chapron C, Chopin N, Borghese B, Foulot H, Dousset B, VacherLavenu MC et al (2006) Deeply infiltrating endometriosis: pathogenetic implications of the anatomical distribution. Hum Reprod 21:1839-1845

35. Hudelist G, Keckstein J, Wright JT (2009) The migrating adenomyoma: past views on the etiology of adenomyosis and endometriosis. Fertil Steril 92:1536-1543

36. Füth H (1903) Beitrag zur Kasuistik der Adenomyome des Uterus. Zentralblatt für Gynaekologie 26:626

37. Renish N (1912) Ein Beitrag zur Adenomyositis uteri et recti. Zeischrift fuer Geburtshilfe und Gynaekologie. 70:585

38. Lockyer C (1918) Fibroids and allied tumours (myoma and adenomyoma). Macmillan and Co., Ltd, London
39. Donnez J (2008) Is accreditation for surgery necessary? World Endometriosis Society e-journal 10:6-7

40. Fernandez H, Deffieux X, Faivre E, Gervaise A (2008) Should we operate deep infiltrating endometriosis? No. "Choose realism instead of idealism". Gynecol Obstet Fertil $36: 214-217$

41. Canis M, Matsuzaki S, Jardon K, Rivoire C, Cotte B, Tamburro S et al (2008) Yes, patients with deep infiltrating endometriosis should be operated! "Prefer optimistic will to pessimistic intelligence!". Gynécol Obstet Fertil 36:218-221

42. Daraï E, Thomassin I, Barranger E, Detchev R, Cortez A, Houry S et al (2005) Feasibility and technical outcome of laparoscopic colorectal resection for endometriosis. Am J Obstet Gynecol 192:394-400

43. Slack A, Child T, Lindsey I, Kennedy S, Cunningham C, Mortensen N, Koninckx P, McVeigh E (2007) Urological and colorectal complications following surgery for rectovaginal endometriosis. BJOG 14:1278-1282

44. Roman H, Bourdel N (2009) Against the systematic use of segmental resection in colorectal endometriosis: do not replace the pain by unpleasant digestive symptoms! Gynecol Obstet Fertil 37:358-362

45. Vercellini P, Crosignani PG, Abbiati A, Somigliani E, Viagano P, Fedele L (2009) The effect of surgery for symptomatic endometriosis: the other side of the story. Hum Reprod Update 15:177-178

46. Payá V, Hidalgo-Mora JJ, Diaz-Garcia C, Pellicer A (2011) Surgical treatment of rectovaginal endometriosis with rectal involvement. Gynecol Surg 8:269-277

47. Roman H, Loisel C, Resch B, Tuech JJ, Hochain P, Marpeau L (2010) Delayed functional outcomes associated with surgical management of rectal endometriosis: giving our patients an informed choice. Hum Reprod 25:890-899

48. Anaf V, El Nakadi I, De Moor V, Coppens E, Zaeleman M, Noel JC (2009) Anatomic significance of a positive barium enema in deep infiltrating endometriosis of the large bowel. World J Surg 33:822-827

49. Pachler J, Wille-Jørgensen P (2005) Quality of life after rectal resection for cancer, with or without permanent colostomy. Cochrane Database Syst Rev 18(2):CD004323, Review

50. Wang G (2009) Rich innervation of deep infiltrating endometriosis. Hum Reprod 24:827-834

51. Al-Jefout M, Dezarnaulds G, Cooper M, Tokushige N, Luscombe GM, Markham R, Fraser IS (2009) Diagnosis of endometriosis by detection of nerve fibres in an endometrial biopsy: a double blind study. Hum Reprod 24:3019-3024

52. Bokor A, Kyama CM, Vercruysse L, Fassbender A, Gevaert O, Vodolazkaia A, De Moor B, Fülöp V, D'Hooghe T (2009) Density of small diameter sensory nerve fibres in endometrium: a semiinvasive diagnostic test for minimal to mild endometriosis. Hum Reprod 24:3025-3032

53. McKinnon B, Bersinger NA, Wotzkow C, Mueller MD (2012) Endometriosis-associatednerve fibers, peritoneal fluid cytokine concentrations, and pain in endometriotic lesions from different locations. Fertil Steril 97(2):373-380

54. Mechsner S, Grum B, Gericke C, Loddenkemper C, Dudenhausen JW, Ebert AD (2010) Possible roles of oxytocin receptor and vasopressin- $1 \alpha$ receptor in the pathomechanism of dysperistalsis and dysmenorrhea in patients with adenomyosis uteri. Fertil Steril 94(7):2541-2546

55. Tokushige N, Russell P, Black K, Barrera H, Dubinovsky S, Markham R et al (2010) Nerve fibers in ovarian endometriomas. Fertil Steril 94:1944-1947

56. Zhang X, Yao H, Huang X, Lu B, Xu H, Zhou C (2010) Nerve fibres in ovarian endometriotic lesions in women with ovarian endometriosis. Hum Reprod 25:392-397 
57. Roman H, Puscasiu L, Kouteich K, Gromez A, Resch B, Marouteau-Pasquier N, Hochain P, Tuech JJ, Scotte M, Marpeau L (2007) Laparoscopic management of deep endometriosis with rectal affect. Chirurgia 102:421-428

58. Vercellini P, Fedele L, Pietropaolo G, Frontino G, Somigliana E, Crosignani PG (2003) Progestogens for endometriosis: forward to the past. Hum Reprod Update 9:387-396
59. Vercellini P, Pietropaolo G, De Giorgi O, Pasin R, Chiodini A, Crosignani PG (2005) Treatment of symptomatic rectovaginal endometriosis with an estrogen-progestogen combination versus low-dose norethindrone acetate. Fertil Steril 84:1375-1387

60. Koninckx PR, Ussia A (2010) Centers of excellence in endometriosis surgery" or "centers of excellence in endometriosis. Gynecol Surg 7:109-111 